Article

\title{
Pedestrians and E-Scooters: An Initial Look at E-Scooter Parking and Perceptions by Riders and Non-Riders
}

\author{
Owain James, J I Swiderski ${ }^{-}$, John Hicks, Denis Teoman and Ralph Buehler *(i) \\ Urban Affairs and Planning, Virginia Tech, Arlington, VA 22203, USA; owainjames@vt.edu (O.J.); \\ swiderski@vt.edu (J.I.S.); jbhicks@vt.edu (J.H.); dteoman@vt.edu (D.T.) \\ * Correspondence: ralphbu@vt.edu
}

Received: 16 September 2019; Accepted: 7 October 2019; Published: 11 October 2019

check for updates

\begin{abstract}
Since 2018, pedestrians in many U.S. cities have been sharing sidewalk space with dockless shared e-scooters. The introduction of e-scooters has received pushback from pedestrians. Complaints reported in the media include e-scooters blocking walkways and sidewalks when parked illegally as well as safety concerns from pedestrians who do not feel safe around moving e-scooters. However, little is known beyond a few initial studies on e-scooter parking and anecdotes about pedestrian perceptions of e-scooter safety. Our case study from Rosslyn, Virginia, helps shed light on these two issues. First, we conducted a survey of 181 e-scooter riders and non-riders asking about their perceived safety around riders of e-scooters and experiences of sidewalks blocked by e-scooters. We found highly divergent responses about safety and sidewalk blocking perceptions from riders and non-riders. Second, we conducted an observational study of 606 parked e-scooters along three mixed-use corridors in Rosslyn to investigate the relationship between the built environment and e-scooter parking. We found that $16 \%$ of 606 observed e-scooters were not parked properly and $6 \%$ (36 e-scooters) were blocking pedestrian right-of-way. Moreover, our survey showed that e-scooter trips in Rosslyn replaced trips otherwise taken by Uber, Lyft, or a taxi (39\%), foot $(33 \%)$, bicycle $(12 \%)$, bus $(7 \%)$, or car $(7 \%)$.
\end{abstract}

Keywords: e-scooters; pedestrians; parking; blocked sidewalk

\section{Introduction}

Since 2018, pedestrians in many U.S. cities have been sharing sidewalk space with dockless shared e-scooters. The debut of shared e-scooters follows the proliferation of shared electric and pedal bikes since 2017 in many U.S. cities. Americans took 38.5 million e-scooter rides in 2018, exceeding the number of rides taken using station-based bike-sharing systems, and far outstripping the number of rides on shared dockless bikes [1,2]. In most systems, e-scooters can be parked anywhere within a given service area. As a flexible means of transport, e-scooters can play a key role in solving the first and last mile problem, filling the gap between a rider's home or destination and public transport stops $[1,3]$. E-scooters can be part of the car-free mobility mix along with bicycles, public transport, and walking [3]. The introduction of e-scooters has received pushback [1]. Complaints reported in the media include e-scooters blocking walkways and sidewalks when parked illegally, as well as safety concerns from pedestrians who do not feel safe around moving e-scooters [3]. However, little is known beyond anecdotes about perceptions of e-scooters and a few studies on e-scooter parking.

Our case study from Rosslyn, Virginia, helps shed light on these two issues. First, we conducted a survey of e-scooter riders and non-riders asking about their perceived safety around riders of e-scooters and experiences of sidewalks blocked by e-scooters. We found highly divergent responses about 
safety and sidewalk blocking perceptions from riders and non-riders. Second, we conducted an observational study along three mixed-use corridors in Rosslyn to investigate the relationship between the built environment and e-scooter parking. We found that $16 \%$ of 606 observed e-scooters were not parked properly, and $6 \%$ (36 e-scooters) were blocking the pedestrian right-of-way. Our definition of properly parked e-scooters followed the Memorandum of Agreement between e-scooter operators and Arlington County, where Rosslyn is located. Accordingly, properly parked e-scooters did not obstruct fire hydrants and valves, street furniture, crosswalks, public right-of-way or public or private property. Moreover, properly parked e-scooters did not impede pedestrian access and did not protrude beyond the curb.

Cities across the country have been experimenting with dockless e-scooters to better understand operators, market demand, and approach to regulations and vendor relationships. Often, cities lack an appropriate regulatory framework to ensure equitable and sustainable operation of the new services when e-scooters first arrive. Local governments, including Arlington, VA, have launched pilot programs and established agreements with the private mobility companies to provide structure to the operation of dockless e-scooters and evaluate their impacts. Our study took place during this pilot program and focused on the neighborhood of Rosslyn in Arlington, VA.

The neighborhood of Rosslyn is situated directly across the Potomac River from the Washington, DC, neighborhood of Georgetown. Rosslyn is a regional employment hub attracting commuters from the Washington Metropolitan Area (District of Columbia, Maryland, and Virginia). Rosslyn had a population of 12,335 [4] and over 28,200 jobs in 2018 [5].In terms of transportation, Rosslyn has a Metrorail stop as well as stops for local, commuter, and regional bus routes. At the time the study was conducted, five companies were permitted to operate 350 e-scooters each in Arlington County. Many of those companies also operated e-scooter fleets in the neighboring jurisdictions of Alexandria, VA, and Washington, DC, with e-scooters freely crossing jurisdictional boundaries.

There are a few emerging studies that already touch on parts of our research questions. Several studies, often administered by local transportation departments, have observed parked shared e-scooters and bikes and calculated shares of e-scooters and bikes blocking the pedestrian right-of-way. For example, a pilot study in Washington, DC found that $8 \%$ of 181 observed shared dockless e-scooters and bikes were parked undesirably [6]. A study in San Jose, California, found that 10\% of 530 observed e-scooters 'disrupted' pedestrian travel and 11 e-scooters (2\%) actually blocked pedestrian right-of-way [7]. The Seattle Department of Transportation (SDOT) found that $4 \%$ of observed shared dockless bikes blocked pedestrian access [8]. Last, in Portland, OR, 3\% of 357 observed e-scooters impeded ramps, curb cuts, or handrails, $5 \%$ completely blocked pedestrian movement, and $8 \%$ partially blocked pedestrian movement [9].

Some studies provided more detail about dockless e-scooter and bike parking. In Seattle, residential and mixed-use zones had much higher proportions of noncompliant devices (compared to commercial areas). SDOT notes that this is likely because sidewalks in those zones were narrowerand thus it was harder for riders to park e-scooters without obstructing access. In commercial zones, $16 \%$ of devices were parked improperly, and $1 \%$ were obstructing access, but in single-family residential zones, $65 \%$ of devices were parked improperly, and $12 \%$ were obstructing access [8].

Few studies have asked riders and non-riders about their opinion of e-scooters. A survey in Washington, DC, found that over $80 \%$ of respondents who did not agree with the e-scooter program had not yet tried the service [6]. We found no studies asking non-riders about safety perception around e-scooters.

\section{Methods}

Our research approach consisted of an online survey of e-scooter riders and non-riders and an observational study of e-scooter parking. The survey of e-scooter riders and non-riders focused on perceived safety and sidewalk blocking of e-scooters. The observational study investigated the relationship between the built environment and e-scooter parking. 


\subsection{Travel Behavior and Safety Perceptions Survey}

The survey portion of our study was conducted using the Qualtrics survey tool. The Virginia Tech Human Research Protection Program approved the survey as exempt from Institutional Review Board (IRB) review. The survey was open for responses from April 4 through April 24, 2019. It was distributed through several online channels, including social media accounts of the Virginia Tech (VT) Master of Urban and Regional Planning program, VT School of Public and International Affairs, and VT National Capital Region campus. The Rosslyn Business Improvement District (Rosslyn BID) also assisted with online survey distribution through their official Twitter account and a weekly email distribution reaching over 10,000 Rosslyn workers and residents. As an incentive to complete the survey, participants were given the option to enter an email address for a chance to win one of four $\$ 50$ Visa gift cards.

The survey's target population was limited to e-scooter riders and non-riders in the Rosslyn area of Arlington County, VA (Figure 1). Survey respondents were first asked whether they had used dockless e-scooters in Rosslyn. For those who had ridden e-scooters, the survey included questions about mode replacement due to the introduction of the e-scooters-both for the most recent trip and travel behavior changes in general. All survey participants, including those who had not used e-scooters, responded to survey questions on perceived safety and the impact of e-scooters, including:

- Perception of safety while walking around riders of dockless e-bikes and e-scooters, docking bikeshare bikes, and non-shared bikes;

- Frequency of blocked sidewalks due to dockless e-bikes and e-scooters, docking bikeshare bikes, and non-shared bikes.

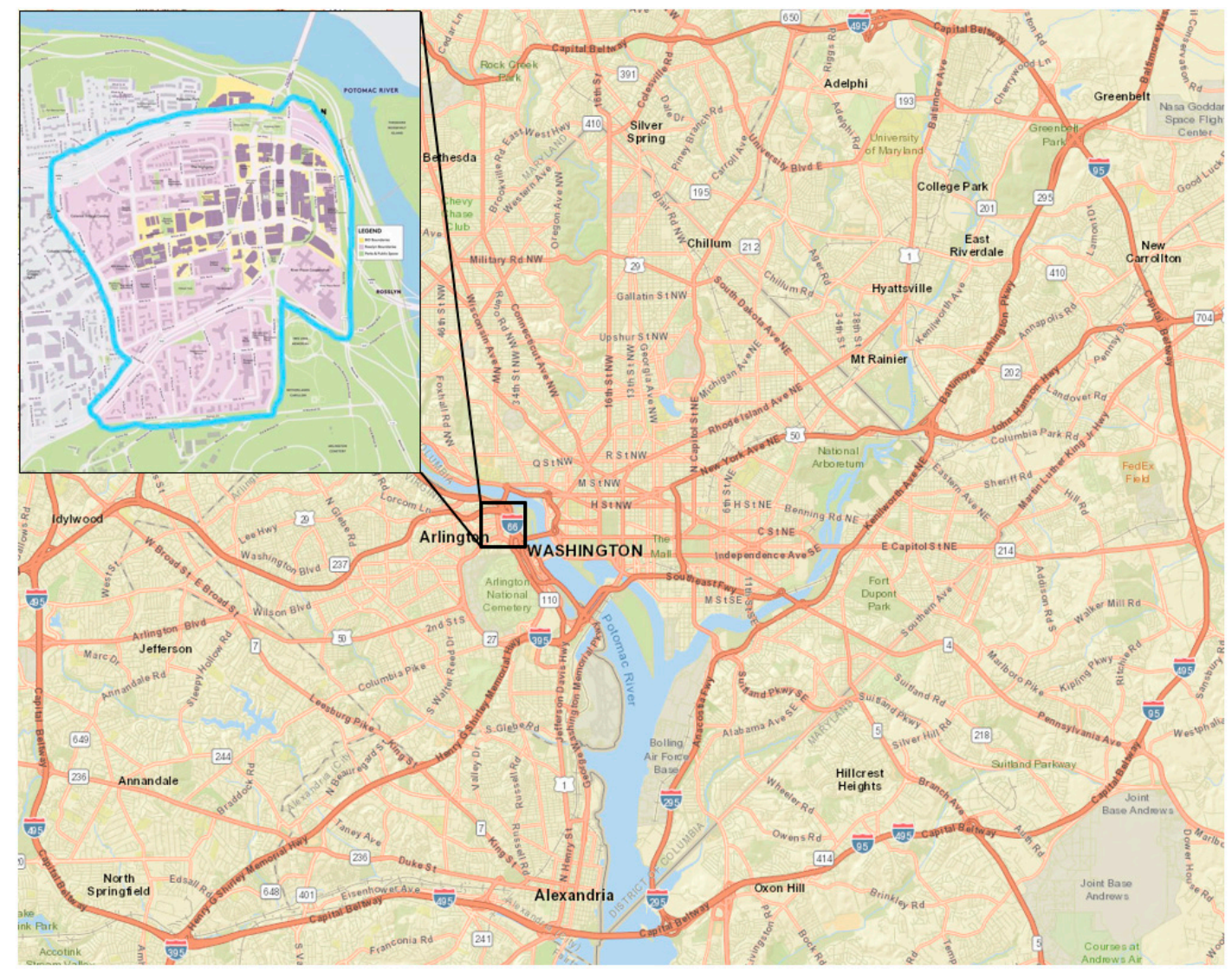

Figure 1. Rosslyn Study Area in Arlington County, Virginia. (Credits: Google Maps/Rosslyn Business Improvement District). 
Respondents answered the safety question on a five-point scale from "very unsafe" to "very safe." For the frequency of blocked sidewalks, respondents were asked to report how often they encountered a blocked sidewalk due to improperly parked dockless e-scooters, docking and dockless bikeshare bikes, and non-shared bikes on a five-point scale from "always" to "never."

Even though not a statistically representative random sample, key socioeconomic and demographic indicators of our survey respondents were roughly comparable to those of the Rosslyn area [5]. For example, $23 \%$ of respondents reported household incomes of less than $\$ 50,000$, compared to $27 \%$ of Rosslyn households. Similarly, $36 \%$ of our respondents and 37\% of Rosslyn households earn more than $\$ 100,000$ per year. Roughly $79 \%$ of Rosslyn residents are between 18 and 44 years old, compared to $70 \%$ in our sample. About $65 \%$ of Rosslyn residents identify as white compared to $69 \%$ in our sample. Finally, women were slightly overrepresented in our sample (56\%) compared to the Rosslyn population $(48 \%)$.

\subsection{Field Observation}

Our observational study aimed to collect data illustrating e-scooter parking practices and how they may differ based on attributes of the built environment. We identified three study areas in or close to the Rosslyn area which had high concentrations of dockless e-scooters. In each area, we established an observation zone consisting of one linear mile of the sidewalk. In Crystal City, we established a $\frac{1}{2}$ mile route along Crystal Dr. and Bell St. and made observations on both sides of the street, while in Rosslyn and Courthouse, we established a 1-mile circuit and made observations on only one side of the street. In Rosslyn, this circuit focused on Wilson Blvd., Lynn St., and Fort Myer Dr., and in Courthouse the circuit was focused on Clarendon and Wilson Blvds. between Courthouse Rd. and Adam St. We conducted 25 observation sessions during different times of day for an entire week-10 in Crystal City, 6 at Courthouse, and 9 in Rosslyn. We conducted weekday observations after the morning and evening commute to be able to observe rider parking behavior (instead of e-scooters parked by company employees during rebalancing of the system or after charging of the e-scooters). Duration of observation sessions varied, depending on the number of improperly parked e-scooters encountered and recorded, but generally ranged between 30 and $50 \mathrm{~min}$.

To collect data, we designed an observational inventory using the smartphone mobile application Epicollect 5. The inventory captured data on time of day, e-scooter location, attributes of the built environment, and e-scooter parking condition, and observers were prompted to take a photo if an e-scooter was improperly parked. Since we returned to the same observation sites over several sessions and did not track individual devices, some e-scooters may have been counted multiple times. It remains unclear if this had an effect on our results because we also counted properly parked e-scooters multiple times if they had not been moved. In addition, our observers parked e-scooters correctly, if the parking condition was dangerous or hazardous for other pedestrians-thus removing the parking violation. We distinguished three sets of attributes of the built environment:

- Street-side attributes (i.e., identifying the use of the road immediately adjacent to the sidewalk);

- Sidewalk attributes (i.e., identifying infrastructure or amenities on the sidewalk);

- Non-street-side attributes (i.e., identifying building and other uses immediately adjacent to the sidewalk).

Table 1 provides more detail on the specific characteristics of the built environment we observed.

We determined street-side attributes by drawing an imaginary line 'through' the center of the parked e-scooter perpendicular to the closest street. We identified attributes that narrow the pedestrian right-of-way (e.g., planters) and attributes whose use could be impaired by improperly parked e-scooters (e.g., sidewalk furniture, like benches). A feature was recorded if the device was within 2 feet $(\sim 60 \mathrm{~cm})$ of it. 
Table 1. Observed Characteristics of the Built Environment.

\begin{tabular}{|c|c|}
\hline Built Environment Element & Attribute of Interest \\
\hline Street-Side Attributes & $\begin{array}{ll}\text { - } & \text { Bike lane } \\
\text { - } & \text { Parking lane } \\
\text { - } & \text { Travel lane }\end{array}$ \\
\hline Sidewalk Attributes & $\begin{array}{ll}\text { - } & \text { Bike parking } \\
\text { - } & \text { Planter, tree, grass strip, traffic and other light posts } \\
\text { - } & \text { Street furniture } \\
\text { - } & \text { Fire hydrant/valve } \\
\text { - } & \text { Bus stop } \\
\text { - } & \text { Bikeshare station }\end{array}$ \\
\hline Non-Street-Side Attributes & $\begin{array}{ll}\text { - } & \text { Restaurant } \\
\text { - } & \text { Offices } \\
\text { - } & \text { Retail } \\
\text { - } & \text { Off-street parking } \\
\text { - } & \text { Residential }\end{array}$ \\
\hline
\end{tabular}

We established and recorded a set of conditions, any of which on its own would constitute improper e-scooter parking. These criteria originated from the Memorandum of Agreement between e-scooter operator companies and Arlington County, which establishes appropriate parking [10]. E-scooter conditions included blocking pedestrian right-of-way, parked on private property, damaging property, not being upright, and obstructing access to fire hydrants, bus stops, street furniture, or bikeshare stations. A complete list of conditions and their definitions is presented in Table 2.

We analyzed the survey results of 181 survey responses and 606 dockless e-scooter observations using Microsoft Excel and the statistical analysis software Stata. In the following results, we present descriptive statistics.

\section{Results}

\subsection{Travel Behavior and Safety Perceptions Survey}

When asked about the means of transport for their last e-scooter trip if e-scooters would not have been available, respondents indicated that they would have used Uber, Lyft, or a taxi (39\%), walked $(33 \%)$, ridden a personal or bikeshare bicycle $(12 \%)$, taken the bus $(7 \%)$, or driven a personal car $(7 \%)$. E-scooter riders also reported their perception of general changes in their personal travel behavior since the launch of e-scooters. The greatest reported decrease in mode usage was for Uber, Lyft, and taxi, with $52 \%$ saying they used those means of transport less often. This was followed by bikeshare $(44 \%)$, driving in a personal or shared car $(35 \%)$, and walking $(28 \%)$.

When asked about safety perception while walking around people using e-scooters, bikeshare bikes, and personal bikes on sidewalks, respondents overall felt safe while walking around non-shared and docked-bikeshare bike riders-with only $11 \%$ feeling "unsafe" or "very unsafe." However, they felt much less comfortable around dockless e-scooter riders, with $56 \%$ of respondents saying they felt "unsafe" or "very unsafe" around dockless e-scooter riders. Respondents felt safer around dockless e-bikes ( $29 \%$ feeling unsafe) but not as safe as they felt around people riding docked and non-shared bikes (11\%). 
Table 2. Observed E-Scooter Conditions.

\begin{tabular}{|c|c|}
\hline Scooter Condition Code & Description \\
\hline Blocking pedestrian right-of-way & $\begin{array}{l}\text { Scooter is impeding pedestrian access or crosswalks. This } \\
\text { includes any e-scooter that does not leave at least five feet of } \\
\text { traversable walkway }\end{array}$ \\
\hline Blocking vehicle right-of-way & Scooter is (even partially) in the street \\
\hline On private property & $\begin{array}{l}\text { Scooter is (even partially), for example, in a driveway, yard, } \\
\text { on a stoop, in a restaurant outdoor seating area, or in a } \\
\text { building nook }\end{array}$ \\
\hline Damaging property (i.e., plants or trees) & $\begin{array}{l}\text { Scooter is leaning against or on top of vegetation or } \\
\text { otherwise in a planter }\end{array}$ \\
\hline Not upright & Scooter is laying on its side or leaning against another object \\
\hline Obstructing access to fire hydrant or valve & Scooter is within two feet of a fire hydrant or valve \\
\hline Obstructing access to street furniture & $\begin{array}{l}\text { Scooter is within two feet of the side of a piece of furniture a } \\
\text { furniture user must access (e.g., for a bench with a back and } \\
\text { armrests, the obstructing side would only be the front of the } \\
\text { bench) }\end{array}$ \\
\hline Obstructing access to bus stop & $\begin{array}{l}\text { Scooter is between the bus stop and the street or within two } \\
\text { feet of either side of the bus stop }\end{array}$ \\
\hline Obstructing access to bikeshare station & $\begin{array}{l}\text { Scooter is within two feet of the side of a bikeshare station a } \\
\text { bikeshare user must access to (un)dock a bike }\end{array}$ \\
\hline
\end{tabular}

While respondents were less comfortable around dockless e-scooters overall, there were striking differences in perceived safety between those whom themselves had experience riding e-scooters and those who did not (Figure 2). Of those who had never ridden an e-scooter before, $76 \%$ reported feeling "unsafe" or "very unsafe" walking around e-scooter riders. In comparison, among respondents who had ridden an e-scooter at least once, only $24 \%$ reported feeling "unsafe" or "very unsafe" while walking around people riding dockless e-scooters. We asked a similar question about respondents' comfort level while driving cars around people riding dockless e-scooters and dockless, docked, and non-shared bicycles, and those results showed a similar difference between feelings about each type of device. Respondents were relatively comfortable driving around people riding their own bike with only $16 \%$ reporting feeling uncomfortable or very uncomfortable, relatively less comfortable around people riding dockless bikes (21\% reported feeling uncomfortable or very uncomfortable), and much less comfortable around dockless e-scooter riders (67\% reported feeling uncomfortable or very uncomfortable). We also found a similar dichotomy between those with experience using the devices and those with no such experience, $80 \%$ of non-riders, but only $47 \%$ of scooter riders reported feeling uncomfortable or very uncomfortable while driving around e-scooters. In fact, almost half (49\%) of non-riders reported feeling very uncomfortable.

When asked how often they encountered blocked sidewalks due to e-scooters, respondents indicated that they came across sidewalks blocked by improperly parked dockless e-scooters much more often than the various bicycle types. More than half (55\%) stated that they encountered a sidewalk blocked by a dockless e-scooter "always" or "often" compared to $18 \%$ for dockless e-bikes (Figure 3). Again, there was a significant disparity between the responses of those who had not used the devices and those who had: Those who had used a dockless e-scooter reported encountering sidewalks blocked by them much less frequently. 


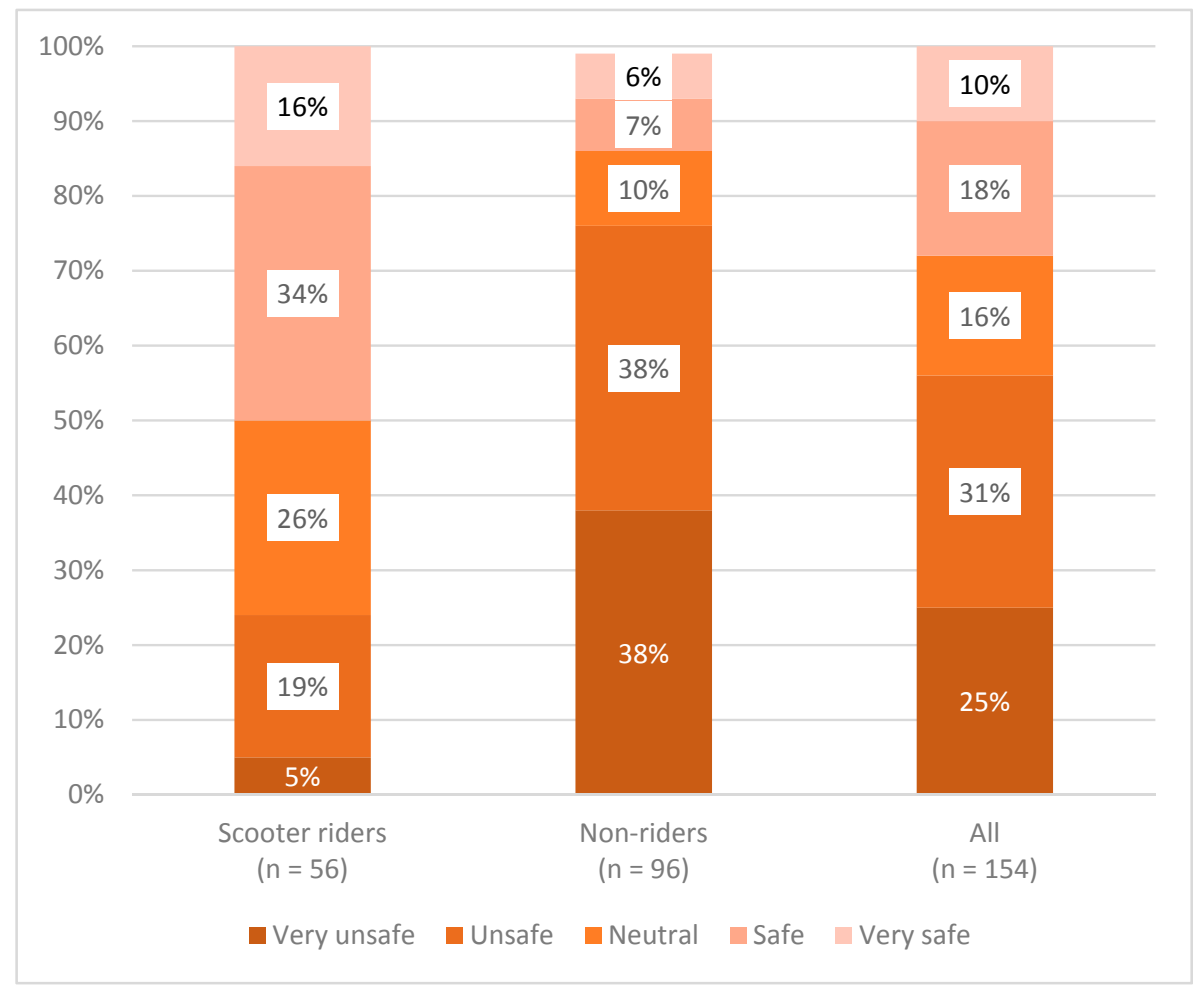

Figure 2. As a pedestrian in Rosslyn, how safe do you feel around riders on dockless e-scooters?

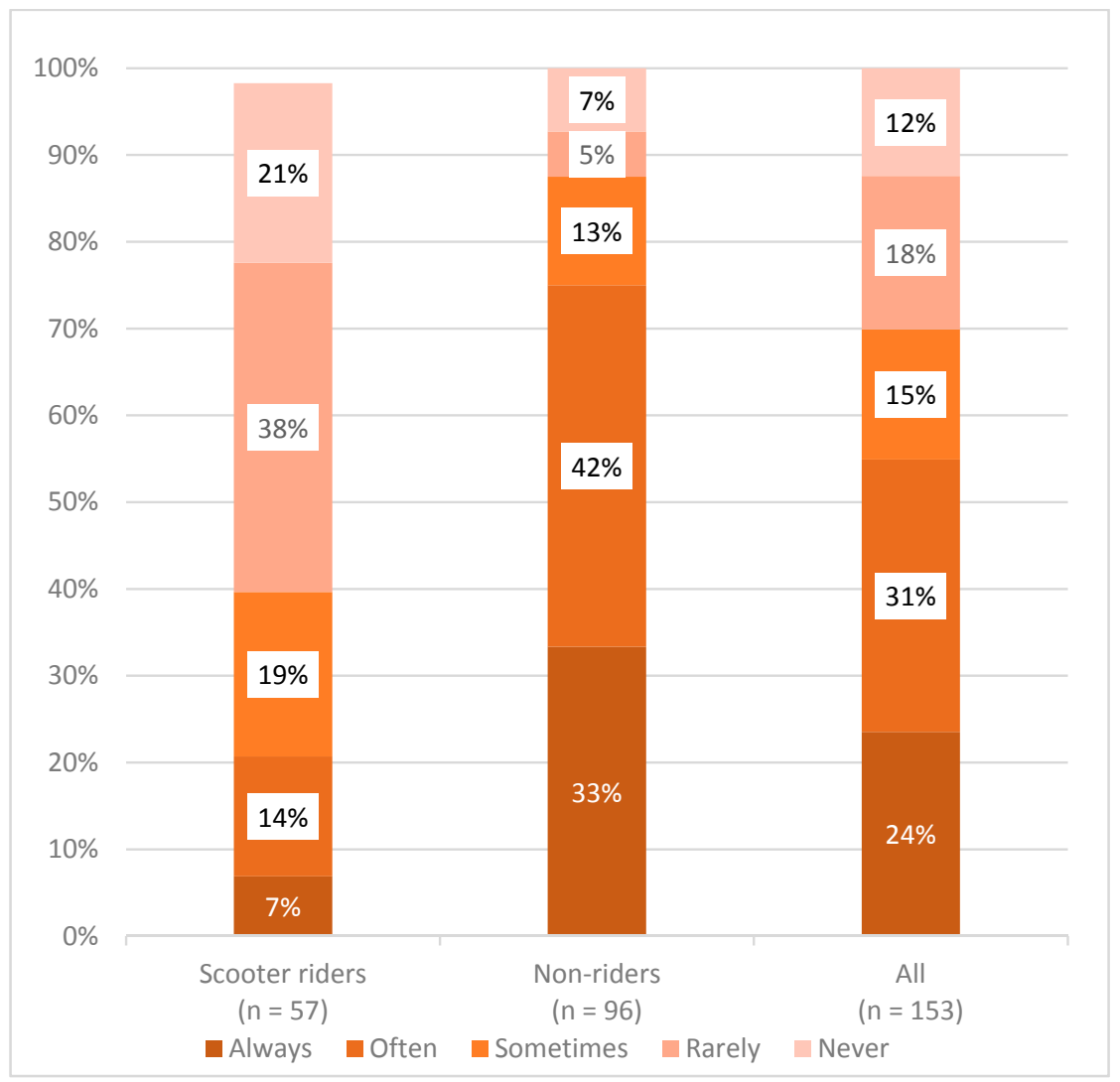

Figure 3. How often do you, as a pedestrian in Rosslyn, encounter blocked sidewalks due to improperly parked dockless e-scooters? 
Our survey also showed that riders and non-riders lack knowledge about e-scooter laws and riding on sidewalks. When asked, high shares of both riders $(43 \%)$ and non-riders $(64 \%)$ stated that they were not familiar with e-scooter laws in Arlington County. In addition, among those who thought they knew about e-scooter laws, there was confusion. For example, only $57 \%$ of riders and $36 \%$ of non-riders correctly stated that e-scooters are not allowed on sidewalks in Arlington County (Figure 4).

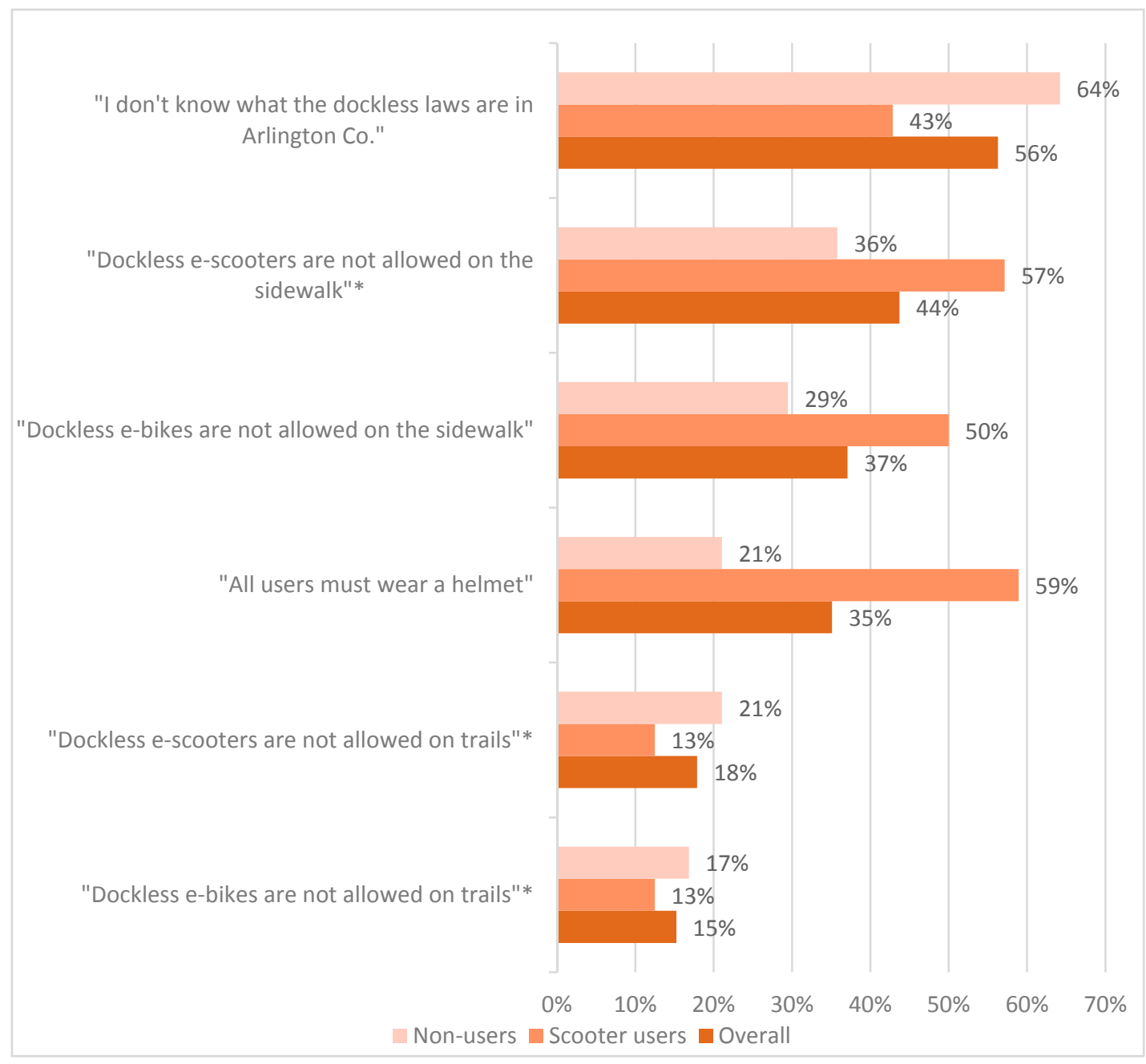

Figure 4. Which of the following are laws related to dockless e-bikes and/or dockless e-scooters in Rosslyn? Note: Participants could choose multiple responses. Two answer choices ("Dockless e-bikes are not allowed in the street" and "Dockless e-scooters are not allowed in the street") with responses of less than $10 \%$ omitted. Answers with "** are actual e-scooter and bike rules in Arlington County.

\subsection{E-Scooter Parking Observation}

Over the course of 25 observation sessions, we recorded a total of 606 parked dockless e-scooters. Of these, $16 \%$ qualified as being parked improperly. The most frequent cases of improper parking were that e-scooters were not upright $(28 \%)$, blocking the pedestrian right-of-way $(23 \%)$, or on private property $(22 \%)$. Other types of improper parking were observed less frequently and included obstructing access to street furniture (11\%), obstructing access to fire hydrants $(6 \%)$, damaging property (e.g., trees or plants) (5\%), obstructing access to a bus stop (3\%), as well as blocking vehicle right-of-way (e.g. driveways) (1\%), and blocking access to bikeshare stations (1\%).

In terms of sidewalk attributes, dockless e-scooters were most likely to be improperly parked near fire hydrants/valves ( $35 \%$ of observed e-scooters at fire hydrants were improperly parked), bus stops $(33 \%)$, bike parking $(24 \%)$, planters or light posts $(19 \%)$, and bikeshare stations $(18 \%)$. For land use, 
e-scooters were most likely to be improperly parked near offices $(25 \%)$, likely due to being parked on private property-one of the offenses we recorded. This was followed by improper parking close to off-street car parking $(19 \%)$, retail $(16 \%)$, restaurants $(16 \%)$, and residences $(13 \%)$. There was almost no difference in improper parking rates based on the use of roadway right-of-way adjacent to parked e-scooters: $19 \%$ of e-scooters parked next to a bike lane were parked improperly, compared to $19 \%$ next to car travel lanes, and $16 \%$ next to car parking lanes.

Overall, only $6 \%$ of the 606 devices were found to be blocking the pedestrian right-of-way. E-scooters were most likely to be parked blocking the pedestrian right-of-way near residential buildings (13\% of e-scooters parked there were blocking right-of-way), offices (10\%), next to fire hydrants $(8 \%)$, and close to bike parking $(7 \%)$, planters $(7 \%)$, and off-street car parking $(7 \%)$. E-scooters blocking pedestrian right-of-way were less likely to be observed close to retail (5\%), restaurants $(3 \%)$, street furniture (5\%), on-street car parking (5\%), and bike lanes $(4 \%)$.

\section{Discussion}

\subsection{Perception of Safety}

Our survey showed that respondents generally felt less safe while walking around dockless e-scooters than they were around the different types of bicycles. We found a similar result for driving around e-scooters. Increased discomfort around e-scooters may be explained by e-scooters being a new mode that pedestrians (and drivers) are not yet used to. For drivers, previous research has found that motorists fail to notice motorcycles at a higher rate than automobiles, likely due to drivers not expecting to see motorcycles, making it difficult to notice them [11]. This phenomenon has been used to explain the inverse correlation between the number of bicyclists and pedestrians and the rate of cyclist and pedestrian crashes. Researchers have found that, as cyclists and pedestrian numbers increase, safety increases, known as the 'safety in numbers effect,' which could be explained by drivers becoming more acclimated to seeing cyclists on the road [12-14]. E-scooters, unlike bicycles and motorcycles, are a new mode of transport, and both riders and drivers are not yet used to how they operate in traffic.

The survey also reveals large differences in comfort and perceived safety between those who had used dockless e-scooters before and those who had not. More than three quarters ( $76 \%$ ) of non-riders reported feeling "unsafe" or "very unsafe" walking around dockless e-scooters while only one quarter $(24 \%)$ of riders felt this way. This could be explained by riders having a greater familiarity with the devices than those who had never ridden them before. A similar difference appeared when respondents were asked to report how frequently they encountered a sidewalk blocked by a dockless e-scooter. One-third of non-riders reported "always" encountering blocked sidewalks while only $7 \%$ of riders reported "always" encountering them. These results are similar toa Washington, DC survey that found that $80 \%$ of respondents who did not approve of the city allowing e-scooters to operate had never tried the service [6] (p. 34).

While these differences could indicate that greater familiarity with dockless e-scooters leads people to be less bothered by them and to feel safer around them, causation is hard to determine. It could also be the case that people who do not like dockless e-scooters and feel uncomfortable around them choose not to use them. In our survey, those who had used dockless e-scooters before were, on average, much younger than those who had not ( $84 \%$ of riders were younger than 34 compared to $45 \%$ of non-riders). This age difference may matter. An e-scooter on the sidewalk might pose a greater challenge to older individuals who may not be able to move the e-scooter out of the way or walk around it as easily as younger respondents.

Moreover, our study did not define what a "blocked" sidewalk was, nor did we quantify the frequency terms we offered (e.g. "always"). Thus, our respondents likely had different ideas about what constitutes a blocked sidewalk when responding to our question. Similarly, it is possible that someone who has experience with using the devices or is able to step over or move them out of the way does not notice how often they have to do so; while, conversely, someone who has more trouble with 
them may notice it more, so that the same number of encounters may seem "frequent" or "infrequent" to different people. We recommend that future studies ask more specifically about the number of instances of blocked sidewalks rather than reporting on the categories we used.

\subsection{Knowledge of Laws}

Respondents, even those who had used dockless e-scooters before, were generally unfamiliar with local e-scooter laws. In Arlington County, e-scooters are not allowed to be ridden on the sidewalk or trails, e-bikes are allowed to be ridden on sidewalks but not trails, and riders of bikes and e-scooters are not required to wear helmets [15]. Of note, $43 \%$ of respondents who had used a dockless e-scooter in Rosslyn reported that they did not know what the laws governing dockless vehicles in Arlington County were. This is a much higher percentage than a similar survey of e-scooter riders in Portland, OR found. In that survey, $26 \%$ of e-scooter riders said they were unfamiliar with e-scooter laws [9]. Portland e-scooter riders were also better at correctly identifying laws; $59 \%$ of Rosslyn e-scooter riders thought that riders were required to wear helmets even though Arlington does not require helmet use. In Portland, which requires riders to wear helmets, $67 \%$ of e-scooter riders correctly said that helmet use was required, while $65 \%$ of Portland riders correctly said that e-scooters were not allowed to be ridden on the sidewalk compared to only $57 \%$ of Rosslyn e-scooter riders.

Rules on sidewalk riding are especially important because of the potential conflicts with pedestrians, but these rules are often confusing. While e-scooters are not allowed on sidewalks in Virginia, e-bikes are, yet $50 \%$ of e-scooter riders and $37 \%$ of all respondents believed e-bikes were not allowed. Different jurisdictions also have slightly different rules, giving riders and pedestrians conflicting messages. Right across the river from Rosslyn in Washington, DC, it is legal to ride e-scooters on the sidewalk in most places, and e-bikes are not allowed to be ridden on the sidewalk anywhere, the opposite of Arlington County [16]. This may lead to confusion for riders and pedestrians who cross between jurisdictions. A similar problem may explain some of the confusion with helmet laws in Arlington County. Some e-scooter companies tell their users to wear helmets before riding, regardless of local regulations.

In order to increase awareness of laws, local jurisdictions should work with e-scooter providers to coordinate and clarify local laws. Where possible, local governments should seek to align their laws. This would make it easier for riders to keep track of laws while travelling across borders. By coordinating with e-scooter providers, local governments can expose riders to one consistent set of rules.

\subsection{Parking}

Though methodology and definitions vary between studies, most researchers divide parked e-scooters and bikes into three groups: correctly parked, incorrectly parked and impeding pedestrian access, or incorrectly parked and not impeding pedestrian access. Our study found that out of 606 total e-scooters observed, $16 \%$ were parked improperly and $6 \%$ were impeding the pedestrian right-of-way. This is comparable to previous studies cited in the literature review above with a range of $8 \%$ to $26 \%$ for improperly parked e-scooters and $4 \%$ to $10 \%$ of e-scooters blocking pedestrian right-of-way [6-9].

In all cases, the vast majority of devices were found to be parked correctly, and a low proportion were found impeding pedestrian access, but this does not mean that parking problems are not prevalent. While $6 \%$ of 606 e-scooters blocking the pedestrian right-of-way may seem low, that is still 35 e-scooters blocking the right-of-way in our relatively small study area. Changes in how "impeding" pedestrians is measured can also drastically change the amount of devices defined as noncompliant. The City of Seattle recently updated their regulations to restrict dockless bikes from being leaned against walls because they can cause a hazard for pedestrians with visual impairments who use a cane to navigate. Re-analyzing their data collected prior to the update, this change reclassified an additional $14 \%$ of devices as impeding access [17]. Arlington rules already prohibit e-scooters being leaned against anything, so such devices are already considered improperly parked in our data. When regulators craft 
rules for dockless bike and e-scooter parking, it is important that they consider and consult all sidewalk users because what constitutes a sidewalk impediment varies for people with different abilities.

Another factor to consider is that improperly parked devices might not be distributed equally geographically-some sidewalks could have a severe impediment, and others could have none. Researchers in Seattle tracked dockless bike parking by land use and found significant differences. A much higher proportion of dockless bikes parked in residential and mixed-use zones were noncompliant. The report notes that this may be explained by these zones having narrower sidewalks, which makes compliant parking more difficult [8].

Though our study areas were all in dense mixed-use built environments, we recorded the land use of the lot closest to the e-scooter. We found that e-scooters were more likely to be parked improperly near offices, mostly explained by e-scooters being left on private property. E-scooters that were blocking the pedestrian right-of-way were much more likely to be found near residential buildings. This might be because commercial and office buildings often have designated bike parking (often also used for e-scooters) for customers and employees near or directly in front of their entrances, while apartment buildings often do not. Clearly demarcating proper parking places for bikes and e-scooters could prevent e-scooters and bikes from being left where they impede access. In this study, we did not find a strong relationship between the presence of bike parking and lower rates of improper parking or pedestrian right-of-way access. However, since the completion of our study, Arlington has implemented bike- and e-scooter-parking corrals, including dedicated space for dockless devices, in several parts of the County. It remains to be seen whether creating those spaces will improve pedestrian-access problems.

Parking for e-scooters seems to be a very controversial issue. However, the introduction of new modes of transport is prone to disrupt existing systems. For example, the emergence of the automobile caused large parking problems $[18,19]$. The solution were off-street parking garages, parking meters, local zoning ordinances requiring minimum off-street car parking spaces, as well as enforcement of car parking. In fact, today most cities employ staff to enforce car-parking regulations and impose fines if warranted. Similarly, illegal 'wild' or 'fly' parking of bicycles (outside of designated areas) has been a problem in countries and cities with high cycling levels-resulting in stricter enforcement of parking regulations and construction of bicycle parking garages [20]. In response to the e-scooter parking problem, municipalities are now starting to devise regulations for e-scooter parking, including geofenced designated areas for e-scooter parking outside of which vendors may not allow a user to end a trip.

\section{Conclusions}

Our observation of e-scooter parking behavior adds to the growing body of research showing that only a small share (4-10\%) of parked e-scooters impede pedestrian access. However, our survey shows that perceptions about the impact of e-scooters vary significantly between those who have used e-scooters before and those who have not. This could indicate that more familiarity with the new devices leads to more moderate views about their impact on sidewalk access and safety. If e-scooters become a permanent fixture on city streets, later studies on perceived safety could test if perceptions change over time. Cities should be aware of this divergence in perception by designing public outreach programs to educate riders and the public about e-scooters.

Our survey also showed that Arlington County's e-scooter laws had not penetrated into the general public. This is understandable due to the recent introduction of the e-scooter pilot program, but indicates that local governments cannot rely on operators and the internet to promulgate laws. E-scooter users and non-users require more direct education, and likely more understandable and streamlined rules between jurisdictions.

A more comprehensive look at sidewalk accessibility is necessary to fully evaluate the impact e-scooters have on sidewalk users. Further research on a variety of sidewalk obstructions, such as automobiles, debris, and signage, is necessary to evaluate if e-scooters are a uniquely bad offender, 
or just the most visible because of their recent arrival. Though research indicates that the share of e-scooters that impede access is small, a more holistic evaluation of their impact on accessibility is necessary. Depending on local conditions, a few impeding e-scooters could be a major barrier or just a minor nuisance.

Author Contributions: The authors confirm contribution to the paper as follows: Study conception and design: O.J., J.I.S., J.H., R.B.; data collection: O.J., J.I.S., J.H.; analysis and interpretation of results: O.J., J.I.S., J.H., R.B.; draft manuscript preparation: O.J., J.I.S., J.H., D.T., and R.B. All authors reviewed the results and approved the final version of the manuscript.

Funding: This research received no external funding.

Acknowledgments: The authors would like to thank Alex Wilkerson and Anika Chowdhury for their help in collecting data during a Virginia Tech graduate level urban planning studio class. The authors thank Virginia Tech's Open Access Subvention Fund (OASF) for helping to pay for article processing charges.

Conflicts of Interest: The authors declare no conflict of interest.

\section{References}

1. Shaheen, S.; Cohen, A. Shared Micromoblity Policy Toolkit: Docked and Dockless Bike and Scooter Sharing; UC Berkeley Transportation Sustainability Research Center: Richmond, CA, USA, 2019; Available online: https://escholarship.org/uc/item/00k897b5 (accessed on 13 September 2019).

2. National Association of City Transportation Officials. Shared Micromobility in the U.S. 2018. Available online: https://nacto.org/shared-micromobility-2018/ (accessed on 12 September 2019).

3. Ajao, A. Electric Scooters and Micro-Mobility: Here's Everything You Need to Know. Available online: https://www.forbes.com/sites/adeyemiajao/2019/02/01/everything-you-want-to-knowabout-scooters-and-micro-mobility/\#66bffe855de6 (accessed on 13 September 2019).

4. U.S. Census Bureau, 2013-2017 American Community Survey 5-Year Estimates. Available online: https: //factfinder.census.gov/faces/nav/jsf/pages/index.xhtml (accessed on 12 September 2019).

5. Arlington, V.A. Rosslyn Sector Plan: A Plan for the Rosslyn Coordinated Redevelopment District. July 2015. Available online: http://arlingtonva.s3.amazonaws.com/wp-content/uploads/sites/31/2015/12/151208_ RosslynSectorPlan-HI.pdf (accessed on 12 September 2019).

6. District Department of Transportation. Dockless Vehicle Sharing Demonstration. Available online: https://ddot.dc.gov/sites/default/files/dc/sites/ddot/publication/attachments/Dockless\%20Demonstration\% 20Evaluation\%20010319.pdf (accessed on 12 September 2019).

7. Fang, K.; Agrawal, A.W.; Steele, J.; Hunter, J.J.; Hooper, A.M. Where Do Riders Park Dockless, Shared Electric Scooters; San Jose State University: San Jose, CA, USA, 2014; Available online: https://transweb.sjsu.edu/sites/ default/files/1713-WP2-Scooter-Parking.pdf (accessed on 9 October 2019).

8. Seattle Department of Transportation. 2017 Free-Floating Bike Share Pilot Evaluation Report. 2017. Available online: https://www.seattle.gov/Documents/Departments/SDOT/BikeProgram/ SDOTBikeShareEvaluationReport2017.pdf (accessed on 12 September 2019).

9. Portland Bureau of Transportation. 2018 E-Scooter Findings Report. Available online: https://www. portlandoregon.gov/transportation/article/709719 (accessed on 12 September 2019).

10. Arlington County, VA, USA. Memorandum of Agreement between [Name of Company] and Arlington County, Virginia. 2018. Available online: https:/arlingtonva.s3.amazonaws.com/wp-content/uploads/sites/19/2018/ 10/SMD-Demonstration-Program-Memorandum_of_Agreement.pdf (accessed on 12 September 2019).

11. Pammer, K.; Sabadas, S.; Lentern, S. Allocating Attention to Detect Motorcycles: The Role of Inattentional Blindness. Hum. Factors Ergon. Soc. 2017, 60, 5-19. [CrossRef] [PubMed]

12. Fyhri, A.; Sundfør, H.B.; Bjørnskau, T.; Laureshyn, A. Safety in Numbers for Cyclists—Conclusions from a Multidisciplinary Study of Seasonal Change in Interplay and Conflicts. Accid. Anal. Prev. 2017, 105, 124-133. [CrossRef] [PubMed]

13. Jacobsen, P.L. Safety in Numbers: More Walkers and Bicyclists, Safer Walking and Bicycling. Inj. Prev. 2003, 9, 205-209. [CrossRef] [PubMed]

14. Jacobsen, P.L.; Ragland, D.R.; Komanoff, C. Safety in Numbers for walkers and bicyclists: Exploring the mechanisms. Inj. Prev. 2015, 21, 217-220. [CrossRef] [PubMed] 
15. Arlington County, VA, USA. Bicycles. Arlington County Code, Chapter 14.2, Article II. 2012. Available online: https://arlingtonva.s3.amazonaws.com/wp-content/uploads/sites/22/2014/01/County-Code14-2-Motor-Vehicles-and-Traffic.pdf (accessed on 31 July 2019).

16. District of Columbia Municipal Regulations, §18-1201.9. Safe Operation of Bicycles, and Motorized Bicycles. Available online: http://dcrules.elaws.us/dcmr/18-1201 (accessed on 13 September 2019).

17. Groover, H. Frustrated by All Those Bikes in the Middle of Seattle Sidewalks? You're Not Alone. Seattle Times. Available online: https:/www.seattletimes.com/seattle-news/transportation/frustrated-by-all-those-bikes-inthe-middle-of-seattle-sidewalks-youre-not-alone/ (accessed on 13 September 2019).

18. Norton, P. Fighting Traffic: The Dawn of the Motor Age in the American City; MIT Press: Cambridge, MA, USA, 2008.

19. Shoup, D. The High Cost of Free Parking; Updated Edition; Routledge: New York, NY, USA, 2011.

20. Heinen, E.; Buehler, R. Bicycle parking: A systematic review of scientific literature on parking behaviour, parking preferences, and their influence on cycling and travel behavior. Transp. Rev. 2019, 39, 630-656. [CrossRef]

(C) 2019 by the authors. Licensee MDPI, Basel, Switzerland. This article is an open access article distributed under the terms and conditions of the Creative Commons Attribution (CC BY) license (http://creativecommons.org/licenses/by/4.0/). 